No. $19-4$

\title{
Estimating the Marginal Propensity to Consume Using the Distributions of Income, Consumption and Wealth
}

\author{
Jonathan Fisher, David Johnson, \\ Timothy Smeeding, and Jeffrey Thompson
}

\begin{abstract}
:
Recent studies of economic inequality almost always separately examine income, consumption, and wealth inequality and, hence, miss the important synergy among the three measures explicit in the life-cycle budget constraint. Using Panel Study of Income Dynamics data from 1999 through 2013, we examine whether these changes are more dramatic at higher or lower levels of wealth and find that the marginal propensity to consume is lower at higher wealth quintiles. This suggests that low-wealth households cannot smooth consumption as much as other households do, which further implies that increasing wealth inequality likely reduces aggregate consumption and limits economic growth.
\end{abstract}

\section{JEL Classifications: E21, D15, D30}

Keywords: Marginal Propensity to Consume, Wealth Distribution, Inequality

Jonathan Fisher is a research scholar at the Stanford Center on Poverty and Inequality; his email is jonathan.fisher@stanford.edu. David Johnson is a research professor at the University of Michigan's Institute for Social Researcher, where he is the director of the Panel Study of Income Dynamics (PSID); his email is johnsods@umich.edu. Timothy Smeeding is the Lee Rainwater Distinguished Professor of Public Affairs and Economics at the University of Wisconsin-Madison's Robert M. La Follette School of Public Affairs; his email is smeeding@lafollette.wisc.edu. Jeffrey Thompson is a senior economist and policy advisor in the research department at the Federal Reserve Bank of Boston, where he is the director of the New England Public Policy Center. His email is jeffrey.thompson@bos.frb.org.

The authors thank Joe Hotz, Adriana Kugler, participants in the PSID User Conference, and participants in the WCEG grantee conference, the IUPUI workshop, and the SOLE annual conference for helpful comments. They offer special thanks to Jonathan Latner (University of Bamberg) for preparing the data set and assisting with the analysis. The authors also thank the Russell Sage Foundation and the Washington Center for Equitable Growth for support of this research, but they hold each organization, as well as their own organizations, harmless from the conclusions of this work.

This paper presents preliminary analysis and results intended to stimulate discussion and critical comment. The views expressed herein are those of the authors and do not indicate concurrence by the Federal Reserve Bank of Boston, the principals of the Board of Governors, or the Federal Reserve System. This paper, which may be revised, is available on the website of the Federal Reserve Bank of Boston at http://www.bostonfed.org/economic/wp/index.htm. 
Studies of economic inequality almost always separately examine income, consumption, and wealth and, hence, miss the important synergy among the three measures explicit in the life-cycle budget constraint. Stiglitz, Sen, and Fitoussi (2009) state, “...[T]he most pertinent measures of the distribution of material living standards are probably based on jointly considering the income, consumption, and wealth position of households or individuals." Recent research shows that these joint distributions are important in evaluating macroeconomic impacts due to the heterogeneity in responses to changes in income and wealth (see Krueger, Mitman, and Perri [2016]).

This heterogeneity in the consumption response to income changes can have a significant impact on the effectiveness of government fiscal policy. Alan Krueger, in his Council of Economic Advisors inequality address (Krueger 2012), suggests that with differential responses to income changes across the distribution, “. . if another $\$ 1.1$ trillion had been earned by the bottom 99 percent instead of the top 1 percent, annual consumption would be about $\$ 440$ billion higher. This would be a 5 percent boost to aggregate consumption." We evaluate this proposition by estimating the differential responses to income changes.

Fisher et al. (2016a) were the first to use the Panel Study of Income Dynamics (PSID) to examine the conjoint distribution of income, consumption, and wealth. Their study finds that the correlation between the three measures is high, but not perfect. This paper advances that earlier work and examines the relationship between the three resource measures, determines how changes in income and wealth affect changes in consumption, and studies whether these changes are more dramatic at lower levels of wealth. The PSID is the only panel data set that includes all three measures over time for the same households. We use the PSID data from 1999 through 
2013 to examine how changes in income and the level of wealth affect changes in consumption, which are then used to calculate the marginal propensity to consume (MPC).

Following a long line of research (see, for example, Zeldes [1989], Hall and Mishkin [1982], Lusardi [1996], Blundell, Pistaferri, and Preston [2008], and Dynan [2012]) that estimates the effects of changes in income on changes in consumption, we estimate the MPC using a broader measure of consumption. Due to the PSID's survey questions, most of the early research uses spending on food as the measure of consumption or an imputed measure of non-durable consumption based on spending on food and demographic characteristics. ${ }^{1}$ In 1999, the PSID introduced a fuller measure of consumption and also started collecting information on wealth in every wave of the survey. Before 1999, the PSID consumption data were limited to spending on food and housing. Therefore, our analysis begins with 1999, and we use consistent measures of consumption, income, and wealth in every wave.

Recent research demonstrates that the MPC differs across the income and wealth distribution. For instance, Kaplan, Violante, and Weidner (2014) find the wealthy hand-to-mouth households, with high illiquid wealth but little liquid savings, have the highest MPC. Johnson, Parker, and Souleles (2006) find that consumption response to the 2001 tax rebates were larger for households with low wealth (and low income). Carroll et al. (2017) examine models that yield a higher MPC for low-wealth households. These differences in the MPC are important in examining the impact of government fiscal policy, as suggested by Krueger (2012). We provide

\footnotetext{
${ }^{1}$ The following papers use the food consumption measure: Morgan (1971), Hall and Mishkin (1982), Altonji and Siow (1987), Zeldes (1989), Dynan (2000), Carroll (1994), Lusardi (1996), Jappelli, Pischke, and Souleles (1998), Ziliak (1998), Stephans (2001), Gourinchas and Parker (2002), Hurst and Stafford (2004), Filer and Fisher (2007), and Gorbachev (2011). Fisher and Johnson (2006), Blundell, Pistaferri, and Preston (2008), Heathcote, Perri, and Violante (2010), Dynan (2012), Attanasio and Pistaferri (2014), Kaplan, Violante, and Weidner (2014), Dogra and Gorbachev (2015), Krueger, Mitman, and Perri (2016), Choi, McGrarry, and Schoeni (2015) and Fisher et al. (2016a) use a broader measure of consumption.
} 
further evidence in support of this research by estimating the MPC by wealth quintile. Ours is also the first paper to test, employing expenditure data, whether the MPC changed following the Great Recession. ${ }^{2}$

Using the changes in income and consumption between pairs of periods (basically, biennial changes), we can estimate the Euler equation for how consumption changes with respect to changes in income. We find that the overall MPC is about 10 percent, which lies at the low end of the range examined in other research. Carroll et al. (2017) provide a table with many of the recent estimates.

We also find that the MPC is lower for the higher-wealth quintiles, which suggests that lowwealth households cannot smooth consumption as much as wealth-holding households at the same income level do, and therefore they respond more to changes in income per se. At the other end, wealthy households can more closely, even if imperfectly, follow the life-cycle/permanentincome hypothesis (LCPIH). Given the differences in MPC across wealth (and income) quintiles, we use the simple method employed by Fixler and Johnson (2014) to illustrate how these different MPCs can be used to construct an autonomous expenditure multiplier that is larger than the standard single MPC multiplier, and, hence, how redistribution to the lower quintiles will stimulate economic growth. These findings support the broad conclusion by Krueger (2012) that aggregate consumption would be higher if income were transferred from high-wealth to lowwealth households.

\footnotetext{
${ }^{2}$ Gross, Notowidigdo, and Wang (2016) use credit card data to estimate the MPC out of credit limit increases before, during, and after the Great Recession. Their sample is limited to card holders who had their bankruptcy flag removed during one of these time periods and therefore had an exogenous increase in their credit limit. The authors' approach is comparable to that of Filer and Fisher (2007), who use the PSID to estimate how bankruptcy-flag removal affects the responsiveness of consumption to changes in income.
} 
At the upper end of the wealth and income distributions, the lower MPC is also reinforced by the rising share of capital income in the System of National Accounts, suggesting that higher-income individuals who hold most of the financial wealth in the economy, and who directly or indirectly hold this income through defined contribution pensions and retained corporate earnings, are less likely to consume from those accretions (Piketty, Saez, and Zucman 2018; Elsby, Hobijn, and Sahin 2013).

\section{Background}

The best way to understand the conjoint distribution is to include income, consumption, and wealth in the same survey. ${ }^{3}$ The PSID has asked about income, consumption, and wealth in every wave since 1999, and so it represents a ready-made source of all three measures, as evidenced by Krueger, Mitman, and Perri (2016) and Fisher et al. (2016a).

Economic theory suggests that a household's well-being (as measured by its utility) depends on its characteristics and its consumption levels. The life-cycle/permanent-income hypothesis (LCPIH) suggests that the household's well-being depends on the current-income stream that occurs over the household's lifetime. The LCPIH assumes a household can smooth consumption through personal savings or credit markets. Given that assumption, a household should change its consumption plans in response to permanent shocks to income and react far less in terms of consumption (responding only to the annuitized value of transitory shocks) if there is uncertainty. At the other extreme, assuming that a household has access to complete markets in which it is able to fully insure against any shocks, its consumption should not react to either

\footnotetext{
${ }^{3}$ Blundell (2014), in his address to the Royal Statistical Society, states the importance of all three measures: “One thing is for sure, the results of the research presented here provide a strong motivation for collecting consumption data, along with asset and earnings data, in new longitudinal household surveys and linked administrative register data."
} 
permanent or transitory income shocks. If a household has access to some insurance mechanism (formal or informal), it will be able to smooth out, at least in part, income shocks.

The LCPIH indicates that a household smooths consumption so that even if income varies significantly over the life cycle, consumption is less variable than income from year to year. In addition, the hump-shaped income and consumption profile reflects the LCPIH, with income rising until middle age and then falling, and consumption following a similar, although less pronounced, hump-shaped pattern.

If households can completely self-insure against income shocks, the MPC out of permanent shocks and the MPC out of transitory shocks are both zero, suggesting that an increase in income inequality generated by changes in permanent or transitory shocks does not affect consumption inequality. Instead, wealth inequality increases, which also increases the capacity to address further shocks and allows greater possibilities for intergenerational wealth transfer. On the other extreme, if households have no ability to self-insure against permanent or transitory income shocks, and thus the MPC out of each instead equals one, then an increase in income inequality completely passes through to consumption inequality, with no change in wealth inequality.

Johnson, Parker, and Souleles (2006) evaluate the consumption response to tax rebates and find that the MPC changes with income and asset levels, yielding a larger MPC for lower-income and liquidity-constrained households. Misra and Surico (2014) further examine this heterogeneity in consumption response and find that the aggregate impact decreases due to these heterogeneous consumption responses.

Following Baker (2018) and Dynan (2012), we estimate an Euler equation for the relationship between the changes in consumption and income. Baker (2018) finds that the income elasticity 
of consumption is 0.3 , which increases with the level of assets (and decreases with debt). Carroll et al. (2017) compare much of this literature, in which the MPC ranges from 0.2 to 0.6 , the latter of which is much greater than what is commonly used in the macroeconomic literature. In fact, Carroll et al. (2017) suggest that "some of the dispersion in MPC estimates from the microeconomic literature (where estimates range up to 0.75 or higher) might be explainable by the model's implication that there is no such thing as 'the' MPC - the aggregate response to a transitory income shock should depend on details of the recipients of that shock in ways that the existing literature may not have been sensitive to (or may not have been able to measure)." Using a model with preference heterogeneity, the authors demonstrate the relationship between wealth and the MPC.

\section{Data and Methods}

It is important to use a consistent theoretical framework to define income, consumption, and wealth. The most comprehensive concept of income and consumption is drawn from the suggestions of Haig and Simons, where income represents the capacity to consume without drawing down net worth. Economists have used the following equation as the working definition of Haig-Simons: Income $(\mathrm{Y})$ equals consumption $(\mathrm{C})$ plus the change in net worth $(\Delta \mathrm{W})$. No studies use this definition to the fullest extent, because no household survey has the necessary variables to create a full measure of Haig-Simons income. ${ }^{4}$ Our research goal is to have measures of disposable income, consumption, and net worth that are accurate and as closely linked as possible given the data limitations. Our measures of income and consumption do not completely characterize the Haig-Simons income measure. One particular category missing from both our

\footnotetext{
${ }^{4}$ Smeeding and Thompson (2011) discuss the Haig-Simons income measure and construct a "More Complete Income" measure that attempts to account for the realized and unrealized returns on asset income.
} 
income and consumption measures is government-provided and employer-provided health benefits, which would lead to lower levels of inequality. Another uncertain category is the level and frequency of some intergenerational inter vivos transfers, which are likely not included in our measures of income or consumption.

Evaluating all three measures requires a data set that includes all three measures, whether it is a panel or a series of cross-sections. In this paper, we use the PSID, which includes all three measures over time. The PSID has collected a broad range of socioeconomic and other information on families since 1968 — on an annual basis until 1997 and biennially since then. The PSID first introduced an extensive wealth module in 1984 and continued to include it every five years until 1999. Since then, the wealth module has been included in every wave. The PSID first introduced a fairly comprehensive measure of consumption in 1999. Before 1999, the PSID consumption data were limited to spending on food and housing. Our analysis starts in 1999, because it is the first year that the survey has all three measures in every wave.

The PSID collects data in the year of the survey. Respondents report their income for the previous taxable year, their wealth for the time of the interview (the survey year); and their consumption for a mixture of time periods. In our analysis, we use the survey year to represent the year for the resource, convert measures to constant 2013 dollars, adjust by family size using an equivalence scale given by the square root of family size, and use the family level file ${ }^{5}$ and longitudinal weights. ${ }^{6}$

\footnotetext{
${ }^{5}$ Results are similar if we exclude the supplemental low-income Survey of Economic Opportunity (SEO) sample and use only the Survey Research Center (SRC) sample.

${ }^{6} \mathrm{We}$ also compare the cross-section results using the family weights, and the results are qualitatively similar.
} 
Total family income is the sum total of taxable, transfer, and social security income of the household head, wife, and other family units. We use after-tax income, imputing taxes by employing a model that Kimberlin, Kim, and Shaefer (2015) constructed with NBER TAXSIM.

Total household wealth is the sum total of eight asset variables minus debt. The asset variables are farm and business, checking and savings, other real estate (for example, second home, land, rental real estate, or money owed on a land contract), stocks, vehicles, other assets (for example, a life insurance policy), annuity/IRA, and home equity. Until 2007, the PSID measure for debt was total debt. As of 2009, debt is the sum total of debt from farm or business, real estate, credit card, student loan, medical, legal, family loan, or other. While the PSID wealth module also covers all major wealth components-namely, housing wealth, a range of financial and real assets, retirement wealth, and various types of liabilities - it draws on fewer survey items than does the Survey of Consumer Finances (SCF). Total wealth estimates produced from the PSID are comparable to those from the SCF. The primary exception is for the wealthiest 1 to 3 percent of households, which the SCF reaches through its IRS oversample and the PSID does not (Juster, Smith, and Stafford 1999; Pfeffer et al. 2016). ${ }^{7}$

The definition of consumption changes in the PSID. In the data before 2003, consumption is the sum total of food, ${ }^{8}$ housing, transportation, education, and child care. Beginning in 2005, consumption also includes spending on travel, clothing, other recreation, home repair, home furnishings, and home phones. Therefore, we use the 1999-2003 measure of consumption over

\footnotetext{
${ }^{7}$ As in the study by Wolff (2016), wealth does not include defined benefit retirement or social security holdings. Future work will attempt to include this pension wealth following Devlin-Foltz et al. (2016)

${ }^{8}$ Following Fisher and Johnson (2006) and Attanasio and Pistaferri (2014), we include the amount of food stamps (or SNAP) in the total food consumption.
} 
the entire period and include a rental value of home ownership that equals 6 percent of the house value.

Several recent papers judge the quality of the PSID income, consumption, and wealth data in comparison to similar surveys. ${ }^{9}$ These papers include a study by Andreski et al. (2014), who show that the PSID consumption measure is similar to that of the Consumer Expenditure Survey (CE). Other research shows the consistency between the PSID and SCF wealth measures, and Krueger, Mitman, and Perri (2016) confirm that the trends in income and consumption from the PSID are similar to the trends shown in the national accounts from the Bureau of Economic Analysis (BEA). ${ }^{10}$ Fisher and Johnson (2006) demonstrate that the PSID captures more income than does the CE, and Andreski et al. (2014) favorably compare the income levels in the PSID to those in the US Census Bureau's Current Population Survey.

Similar to Krueger, Mitman, and Perri (2016), we use this conjoint distribution to examine the differential effects of changes in income and wealth on changes in consumption. These differential effects have important consequences for changes in the economy. If consumption is more sensitive to changes for low-wealth households, distributional changes can impact changes in aggregate consumption.

\section{Results}

Before estimating the marginal propensity to consume (MPC), we first establish that the average propensity to consume (APC) differs by wealth. Fisher et al. (2016a) document that the APC falls with income, that it is above 0.8 for the bottom 10 percent of the income distribution and

\footnotetext{
${ }^{9}$ See Pfeffer et al (2016) for a comparison of the wealth data.

${ }^{10}$ Dettling et al. (2015) suggest that only the SCF has levels of wealth accumulation that correspond well to the national aggregates in the Financial Accounts from the Federal Reserve.
} 
below 0.6 for the top 10 percent. Table 1 shows the APC by wealth quintile and by income quintile for 1999 and 2013. ${ }^{11}$ As expected, there is a negative relationship between wealth quintile and APC, with an APC of 0.74 for the bottom wealth quintile and an APC of 0.61 for the top wealth quintile. The APC falls more by income quintile than by wealth quintile, but this is expected because savings is positively correlated with income (Dynan, Skinner, and Zeldes 2004).

\section{Estimating the Marginal Propensity to Consume}

To examine the impact of income changes on consumption inequality, we need to construct the changes in income and consumption over time. Figures 1A and 1B illustrate our results. Figure 1A, a scatter plot of changes in income and changes in consumption between 2005 and 2007, shows that there are many households with very different changes in their income and consumption over the two-year period. But the unconditional relationship indicates a positive correlation between changes in income and changes in consumption, with a coefficient of $0.18 .^{12}$ Figure 1B limits the households to those in the top and bottom wealth quintiles (black for the top and red for the bottom). While the dispersion is similar, the unconditional relationship for each quintile is different. The bottom quintile shows a higher coefficient (0.37) than the top quintile (0.10), illustrating that households at the bottom of the wealth distribution have a higher MPC than those at the top. ${ }^{13}$

\footnotetext{
${ }^{11}$ The APC for each is low since the estimate of consumption in the PSID includes only 80 percent of total consumption.

${ }^{12}$ Similar to JP Morgan Chase (2015), which employs a panel of consumers who use a JP Morgan Chase-affiliated credit card and JP Morgan Chase-affiliated checking account to measure the volatility of income, we find that almost half of PSID families experience large changes in income and consumption (greater than $+/-30$ percent). Future work will attempt to identify the characteristics of the households with these large differences.

${ }^{13}$ Krueger, Mitman, and Perri (2016) calculate the changes in mean consumption (and income and wealth) before and after the recession and find that the lowest quintile has the largest impact on the change in consumption over this period.
} 
We now turn to our estimation of the impact of income changes on consumption. Following Baker (2018), we estimate the Euler equation (below) for the change in log consumption on the change in log income, with demographic controls, $Z$. The controls for year indicate the changing nature of consumption over the Great Recession (2007 to 2009), when the largest fall in consumption occurred.

$$
\Delta \ln C_{i t-2}=\alpha+\beta \Delta \ln Y_{i t-2}+\delta Z_{i t-2}+\rho_{1} \text { state }_{i t-2}+\rho_{2} \text { year }_{i t-2}+\varepsilon_{i}
$$

The dependent variable is the change in log consumption between $t-2$ and $t$ for household $i$, and the key independent variable is the change in log income between $t-2$ and $t$. The coefficient on the change in log income provides an estimate of the elasticity. To obtain the MPC, we need to multiply the elasticity by the APC. All models include state and year fixed effects. We pool all families in the 1999-2013 observation period, yielding data for more than 35,000 families. We cluster the standard errors for repeat families and use the longitudinal weights in the regressions.

Table 2 shows the various versions of the model. Each version includes the change in log income, and the columns show how the inclusion of additional controls affects the income elasticity. Column (a) shows the base model with only year dummies and state fixed effects; (b) adds the control variables of age group, number of adults and children, marital status, race/ethnicity, and whether there were changes in marital status and family size between waves. As shown in Table 2, when using the base model, the overall income elasticity of consumption is about 0.10. Given an APC of 0.8, this implies an MPC of 8 percent. While this MPC is lower than the MPC found by Carroll et al. (2017), it could be because the PSID's biennial collection of data leads to a recording of smaller changes. Dynan (2012) and Oh and Reis (2012) also find an MPC of about 10 percent. 
These elasticities (and the respective MPC of each) are lower than those found by Baker (2018). This also could be due to the time period; Baker (2018) uses changes in quarterly income and consumption, while the PSID records biennial changes. We also include asset variables and the interaction with the change in log income (following Baker [2018]). Similar to the findings of Baker (2018) and others (see Johnson, Parker, and Souleles [2006]), the income elasticity of consumption falls with the level of assets. Column (c) adds an interaction term between the change in log after-tax income and debt/assets; (d) adds an interaction term between the change in log after-tax income and debt/income; (e) adds an interaction term between the change in log after-tax income with net assets. Like those of Carroll et al. (2017), each of our estimates uses a time period that is shorter than two years. Kaplan, Violante, and Weidner (2014) use the PSID to determine the MPC for the wealthy hand-to-mouth consumers. Using a technique to determine the transitory responses, they find an MPC of about 30 percent. Again, our MPC estimates include all income changes (both permanent and transitory), and, hence, they are smaller than previous estimates. The key result is that, similar to the findings of Kaplan, Violante, and Weidner (2014), the MPC for the lowest-wealth consumers is much larger than the MPC for the highest-wealth consumers.

The Marginal Propensity to Consume by Wealth

To show the importance of wealth as a form of self-insurance, we include interaction terms with the change in income and the household's wealth quintile.

$$
\Delta \ln C_{i t-2}=\alpha+\alpha_{1} \text { Wealth } Q_{i t-2}+\beta \Delta \ln Y_{i t-2}+\gamma \Delta \ln Y_{i t-2} * \text { Wealth } Q_{i t-2}+\delta Z_{i t-2}+\varepsilon_{i}
$$

Using the base model (b) in Table 2, we create net wealth quintiles based on net wealth in year t2 (for example, for 1999 through 2001, we use 1999 net wealth). We create a new variable for 
being in the wealth quintile $\left(\right.$ Wealth $\left.Q_{i}\right)$ and then interact this with the change in log income variable to see if consumption is less responsive at higher wealth.

Table 3 shows the results for the 1999-2013 period. Again, we pool all households over the waves and use clustered standard errors, and control for demographics. The first panel provides the income elasticity of consumption of 0.141 for the bottom quintile and shows that the highest wealth quintile has an elasticity that is lower by 0.112 , or $0.029 .{ }^{14}$ Also note that the elasticity for the third wealth quintile is not statistically different from the elasticity for the lowest wealth quintile. The second and fourth wealth quintiles have an elasticity that is about half as large as that of the bottom quintile. As shown by Fisher et al. (2016b), the economic gains in recent years have gone to the top quintile, while the remaining four quintiles have experienced declines in the share of resources held. Thus, it seems that the extra wealth held by the fourth quintile has not helped these households self-insure against income shocks.

\section{Liquidity Constraints, the LCPIH, and Measurement Error}

Because income and consumption both can suffer from measurement error, we follow Filer and Fisher (2007) to conduct a two-stage model using predicted income. The basic LCPIH model predicts that households do not respond to predictable income changes, and thus consumers behaving as if they follow the LCPIH would not alter their consumption in the face of predictable positive changes or predictable negative changes. For predictable positive changes, households would borrow against future income, and for predictable negative changes they would draw down savings. However, the consumption of households that do not follow the LCPIH could react to predictable changes in consumption.

\footnotetext{
${ }^{14}$ We discuss how each of these elasticities translates into an MPC below.
} 
The model can be refined to separate out households that are borrowing constrained or liquidity constrained from myopic households. The consumption of a borrowing-constrained household reacts to predictable increases in household income because the household is unable to borrow against future income, but it self-insures against predictable negative shocks through its savings and therefore does not respond to predictable negative income shocks. The consumption of a myopic household, on the other hand, responds to predictable negative and positive income changes. It neither borrows nor saves in advance of predictable income changes. Previous research finds that high-wealth households are more likely to follow the LCPIH, while lowwealth households are myopic (Zeldes 1989; Runkle 1991). Thus, we will interact the predictable changes in income with the wealth quintile.

We predict the income change following the model of Filer and Fisher (2007), and for households that have a predicted increase in income, the variable for positive change is the predicted value. ${ }^{15}$ It is zero for households that have a negative predicted change in income. We use these variables in a regression (shown in Table 4) in which, for households that have a predicted negative change in income, the negative income change variable is the predicted decrease; for households that have a predicted positive increase, the negative income change variable equals zero. This allows us to examine the differential impact of increases or decreases in income on consumption. The results tell us how households might respond to predictable income transfers by wealth quintile, again providing evidence on how a predictable transfer from high-wealth households to low-wealth households would affect aggregate consumption.

\footnotetext{
15 The sample size is smaller than that used in Table 3, since we are including only those households for which we can predict income.
} 
The first column in Table 4 combines the positive and negative changes into one variable and shows that the bottom three quintiles react to predictable changes in income, violating the LCPIH. The top two wealth quintiles have no response to predictable changes in income, as the main effect of 18.8 percent is completely offset by the interaction term for the top quintiles. This first column also yields a slightly larger elasticity than in Table 3 . These higher elasticities for the bottom wealth quintile are similar to those obtained by Carroll et al. (2017), who also find elasticities of nearly zero for the top wealth quintile.

The second and third columns of Table 4 test whether the households are myopic or borrowing constrained. Households in the bottom two wealth quintiles increase consumption by 24 percent in response to predictable income increases, while households in the three top wealth quintiles have no consumption response to positive income shocks. None of the wealth quintiles appear to respond to predictable negative income shocks. Combined, the results suggest that households in the bottom two wealth quintiles are borrowing constrained, while households in the top three wealth quintiles follow the LCPIH. The use of predictable changes yields a larger MPC, and a larger difference between the top and bottom wealth quintiles, which suggests that examining the permanent and transitory components are an important next step. ${ }^{16}$ These results show that consumption is more responsive to positive income changes than to negative income changes. In a recent study, Baugh et al. (2018) find that a positive change in income leads to a larger response than does the equivalent negative change in income. Specifically, they find that consumers who receive a tax refund react by spending the refund, while consumer who have to make tax payments do not cut their spending.

\footnotetext{
${ }^{16}$ One possible improvement is to use the models by Blundell, Pistaferri, and Preston (2008) and Kaplan, Violante, and Weidner (2014) and use the residuals from the regressions in changes in income and consumption to determine each MPC (similar to the way that Choi, McGrarry, and Schoeni [2015] do).
} 


\section{Sensitivity Tests}

Tables 5A through 5E compare the results using different samples and consumption measures. Tables 5A and 5B show that excluding house value from wealth and restricting the sample group to non-elderly adults do not change the results. Tables 5C, 5D, and 5E compare the results when using alternative measures of consumption. Using a broader consumption measure (which includes more components after 2007) or a more restricted consistent measure finds a similar relationship for high-wealth households. Following earlier research that uses the PSID for consumption data, we use food at home as the measure of consumption and obtain a larger MPC overall and a smaller MPC for each of the top three wealth quintiles.

\section{Estimating an Aggregate Consumption Multiplier}

Following Fixler and Johnson (2014), we use these differential elasticities (and the corresponding MPC for each) and calculate a simple expenditure multiplier that does not incorporate any behavioral responses. The purpose of the example below is not to add to the discussion about the magnitude of the multiplier, but rather to show in a simplified way how the incorporation of income distribution might impact an expenditure multiplier. Fixler and Johnson (2014) consider a simple closed Keynesian model (similar to that of Chipman [1950]) in which the expenditure component captures all expenditures. ${ }^{17}$ To compare that model with the simple textbook multiplier that assumes a constant MPC, we divide the $N$ sector multiplier by $1 / N$ and obtain the textbook, $1 /(1-m p c)$.

To produce each MPC, we use the elasticities from the model and the APC by quintile shown in Table 1. Table 1 demonstrates the usual fall in the APC as income increases; however, in each

\footnotetext{
${ }^{17}$ Blinder (1975) also uses a simple method to examine redistribution by quintiles.
} 
case, the APC is lower than the one obtained using the Consumer Expenditure Survey data and lower than the one obtained by Fisher et al. (2016b) using the Survey of Consumer Finance. Using positive income shock results to simulate a transfer of resources, Table 4 suggests that the elasticities by wealth quintile are $\{0.240,0.210,0.003,0.003,0.021\}$. Using the APC figures in Table 1 (adjusted for the fact that the PSID consumption data captures about 80 percent of total consumption) and the elasticities, we can determine the MPC by wealth category, $\{0.218,0.166$, $0.002,0.002,0.015\}^{18}$

Using the simple MPC by wealth quintile yields a multiplier of 1.1 compared with the multiplier for a constant MPC of $1.09 .{ }^{19}$ As a result, an equalizing redistribution has a small positive impact on aggregate consumption. Another way to view the impact of a heterogeneous MPC is to compare a transfer to everyone with a transfer targeted to the bottom wealth quintile. While the overall multiplier is 1.1 , the targeted transfer yields a larger multiplier of 1.24 (due to the initial effect of the higher MPC at the bottom of 0.218). ${ }^{20}$ Our multipliers are different from those implied by Krueger (2012), because they provide additional growth from new money, whereas Krueger's (2012) estimate was for overall economic growth. We also expect our multiplier to be lower than the one estimated by Krueger (2012) because we examine differences by quintile, while Krueger focuses on

\footnotetext{
18 The MPC is found by using the APC and assuming that the elasticity of consumption with respect to income, e (as in Dynan [2012] and Oh and Reis [2012]). Since e = MPC/APC, then the MPC for the bottom quintile is 0.24 times the APC in Table 1 (using the medians for 2013).

${ }^{19}$ The overall multiplier is $1 /(1-0.08)$ using the average MPC of 0.08 . For details on the calculation, see Fixler and Johnson (2014).

${ }^{20}$ The targeted multiplier is basically the overall multiplier plus the difference in the MPCs for the initial impact (.218-.08).
} 
the top 1 percent. The top 1 percent have a smaller APC than the next 19 percentiles (see Fisher et al. [2017]). ${ }^{21}$

\section{Conclusions and Next Steps}

We are the first to use the PSID to estimate the MPC by wealth and, hence, provide insight into the joint distribution of income, consumption, and wealth. We find that the overall MPC lies at the low end of the range examined in other research. Our MPC is expected to be lower because we look at two-year changes in income and consumption, while the previous research uses changes over shorter periods of time. We also find that the MPC is lower for higher-wealth quintiles, which suggests that low-wealth households cannot smooth consumption as much as wealth-holding households at the same income level do, and therefore they respond more to changes in income per se. At the other end, wealthy households can more closely, even if imperfectly, follow the life-cycle/permanent-income hypothesis.

These findings support the broad conclusion by Krueger (2012) that aggregate consumption would be higher with a transfer from high-wealth households to low-wealth households. In addition, precautionary savings could rise if income were transferred from high-wealth to lowwealth households. But the extent of these differences is smaller than that in Krueger's estimates. He claims that if $\$ 1.1$ trillion had been earned by the bottom 99 percent of the income distribution instead of the top 1 percent, annual consumption would be about $\$ 440$ billion higher, a 5 percent boost to aggregate consumption. Our estimates suggest that a $\$ 1.1$ trillion boost to the bottom wealth quintile, as opposed to the top, would generate an additional $\$ 230$ billion in

\footnotetext{
${ }^{21}$ The sample size in the PSID does not allow us to reliably capture the top 1 percent, preventing us from estimating a number equivalent to that of Krueger (2012).
} 
consumption. ${ }^{22}$ We expect our estimate to be lower because we focus on the differences in consumption by quintiles.

Our data, however, run only through 2013, and aggregate housing values and financial assets have increased substantially since then (see Bricker et al. [2016]). Furthermore, the PSID does not include those households at the top few percentiles of the wealth distribution. As a result, the PSID (as compared with the SCF) misses about 40 percent of total net worth, which is held by the top 1 percent of wealth holders, where greater financial wealth accumulates (Piketty, Saez, and Zucman 2018).

In the future, we plan to further examine other methods for separating the transitory income changes from the permanent ones (including the methods employed by Kaplan, Violante, and Weidner [2014] and Blundell, Pistaferre, and Preston [2008]), and use the data to estimate the MPC with respect to changes in wealth. We also plan to use the longitudinal nature of the PSID to create a household balance sheet and a Haig-Simons measure of income such that income equals consumption plus the change in wealth. The PSID is the only US data set that allows for a full creation of a Haig-Simons measure of income, because it is the only data set with income, consumption, and the change in wealth over time. This allows us to further examine the relationship between wealth and income changes and their effect on consumption or otherwise classified wealth transfers.

The rise, fall, and change in wealth have been instrumental in financing consumption and, more generally, stabilizing incomes. The explosion and implosion in home values, the main asset of the middle class, can be juxtaposed with the increase in the longer-term value of financial assets,

\footnotetext{
${ }^{22} \mathrm{~A}$ boost to the bottom quintile yields an additional $\$ 154$ billion compared with an equally distributed boost, while a boost to the top quintile yields $\$ 77$ billion less than an equally distributed boost.
} 
which has benefited mainly the rich and the elderly. These asset holdings give parents and grandparents massive leverage to affect their children's ability to pay for college, find good jobs, finance homes, and purchase other key goods that enhance the fortunes and status of younger generations. In this work, we have only begun to scratch the surface of these effects, in so far as they are reflected in consumption as measured in the PSID. 


\section{References}

Altonji, Joseph G., and Aloysius Siow. 1987. "Testing the Response of Consumption to Income Changes with (Noisy) Panel Data." Quarterly Journal of Economics 102(2): 293-328.

Andreski, Patricia, Geng Li, Mehmet Zahid Samancioglu, and Robert Schoeni. 2014. "Estimates of Annual Consumption Expenditures and Its Major Components in the PSID in Comparison to the CE." American Economic Review 104(5): 132-135.

Auclert, Adrien, and Matthew Rognlie. 2018. "Inequality and Aggregate Demand.” NBER Working Paper No. 24280.

Baker, Scott R. 2018. "Debt and the Consumption Response to Household Income Shocks: Validation and Application of Linked Financial Account Data." Journal of Political Economy 126(4): 1504-1557.

Baugh, Brian, Itzhak Ben-David, Hoonsuk Park, and Jonathan A. Parker. 2018. "Asymmetric Consumption Response of Households to Positive and Negative Anticipated Cash Flows." NBER Working Paper No. 25086.

Blinder, Alan S. 1975. "Distribution Effects and the Aggregate Consumption Function." Journal of Political Economy 83(3): 447-475.

Blundell, Richard, Luigi Pistaferri, and Ian Preston. 2008. "Consumption Inequality and Partial Insurance.” American Economic Review 98(5): 1887-1921.

Blundell, Richard. 2014. "Income Dynamics and Life-Cycle Inequality: Mechanisms and Controversies." The Economic Journal 124(576): 289-318.

Bricker, Jesse, Alice Henriques, Jacob Krimmel, and John Sabelhaus. 2016. "Measuring Income and Wealth at the Top Using Administrative and Survey Data." Brookings Papers on Economic Activity 47(1): 261-331.

Carroll, Christopher D. 1994. "How Does Future Income Affect Current Consumption?" Quarterly Journal of Economics 109(1): 111-147.

Carroll, Christoper, Jiri Slacalek, Kiichi Tokuoka, and Matthew N. White. 2017. "The Distribution of Wealth and the Marginal Propensity to Consume." Quantitative Economics 8(3): 977-1020.

Chipman, John S. 1950. “The Multi-Sector Multiplier.” Econometrica 18(4): 355-374.

Choi, HwaJung, Kathleen McGrarry, and Robert F. Schoeni. 2015. "Liquidity Constraints, the Extended Family, and Consumption." University of Michigan, Michigan Retirement Research Center Working Paper 320.

Dettling, Lisa J., Sebastian J. Devlin-Foltz, Jacob Krimmel, Sarah J. Pack, and Jeffrey P. Thompson. 2015. "Comparing Micro and Macro Sources for Household Accounts in the United States: Evidence from the Survey of Consumer Finances." Finance and Economics Discussion Series 2015-86. Board of Governors of the Federal Reserve System.

Devlin-Foltz, Sebastian, Alice M. Henriques, and John E. Sabelhaus (2016). "The Role of Social Security in Overall Retirement Resources: A Distributional Perspective," FEDS Notes 201607-29. Board of Governors of the Federal Reserve System (U.S). 
Dogra, Keshav, and Olga Gorbachev. 2015. "Consumption Volatility, Liquidity Constraints and Household Welfare." The Economic Journal 126(597): 2012-2037.

Dynan, Karen, 2000. "Habit Formation in Consumer Preferences: Evidence from Panel Data." American Economic Review 90(3), 391-406.

Dynan, Karen. 2012. "Is a Household Debt Overhang Holding Back Consumption?” Brookings Papers on Economic Activity 43(1): 299-362.

Dynan, Karen E., Jonathan Skinner, and Stephen P. Zeldes. 2004. "Do the Rich Save More?" Journal of Political Economy 112(2): 391-406.

Elsby, Michael W. L., Bart Hobijn, and Aysegul Sahin. 2013. "The Decline of the U.S. Labor Share." Brookings Papers on Economic Activity 44(2): 1-63.

Filer, Larry, and Jonathan D. Fisher. 2007. "Do Liquidity Constraints Generate Excess Sensitivity in Consumption? New Evidence from a Sample of Post-Bankruptcy Households." Journal of Macroeconomics 29(4): 790-805.

Fisher, Jonathan D., and David S. Johnson. 2006. "Consumption Mobility in the U.S.: Evidence from Two Panel Data Sets." The B.E. Journal of Economic Analysis \& Policy 6(1): 1-38.

Fisher, Jonathan, David Johnson, Jonathan P. Latner, Timothy Smeeding, and Jeffrey Thompson. 2016a. "Inequality and Mobility Using Income, Consumption, and Wealth for the Same Individuals." RSF: The Russell Sage Foundation Journal of the Social Sciences 2(6): 44-58.

Fisher, Jonathan, David Johnson, Timothy Smeeding, and Jeffrey Thompson. 2016b. "Inequality in 3D: Income, Consumption and Wealth.” Washington Center for Equitable Growth Working Paper Series (updated 2017).

Fixler, Dennis, and David S. Johnson. 2014. "Accounting for the Distribution of Income in the US National Accounts.” In Measuring Economic Stability and Progess, edited by Dale W. Jorgenson, J. Steven Landefeld, and Paul Schreyer, 213-244. Chicago, IL: University of Chicago Press.

Gorbachev, Olga. 2011. "Did Household Consumption Become More Volatile?" American Economic Review 101(5): 2248-2270.

Gourinchas, Pierre-Olivier, and Jonathan A. Parker. 2002. "Consumption over the Life Cycle." Econometrica 70(1): 47-89.

Gross, Tal, Matthew J. Notowidigdo, and Jialan Wang. 2016. "The Marginal Propensity to Consume over the Business Cycle.” NBER Working Paper No. 22518.

Hall, Robert E., and Frederic S. Mishkin. 1982. "The Sensitivity of Consumption to Transitory Income: Estimates from Panel Data on Households." Econometrica 50(2): 461-482.

Heathcote Jonathan, Fabrizio Perri, and Giovanni L.Violante. 2010. "Unequal We Stand: An Empirical Analysis of Economic Inequality in the United States, 1967-2006." Review of Economic Dynamics 13(1): 15-51.

Hurst, Erik, and Frank Stafford. 2004. "Home Is Where the Equity Is: Mortgage Refinancing and Household Consumption." Journal of Money, Credit and Banking 36(6): 985-1014. 
Jappelli, Tullio, Jörn-Steffen Pischke, and Nicholas S. Souleles. 1998. "Testing for Liquidity Constraints in Euler Equations with Complementary Data Sources." Review of Economics and Statistics 80(2): 251-262.

Johnson, David, Jonathan Parker, and Nicholas Souleles. 2006. "Household Expenditure and the Income Tax Rebates of 2001.” American Economic Review 96(5): 1589-1610.

Juster, Thomas, James Smith, and Frank Stafford. 1999. "The Measurement and Structure of Household Wealth." Labour Economics 6(2): 253-275.

JP Morgan Chase \& Co. Institute. 2015. Weathering Volatility: Big Data on the Financial Ups and Downs of U.S. Individuals. New York, NY: JP Morgan Chase \& Co Institute.

Kaplan, Greg, Giovanni L. Violante, and Justin Weidner. 2014. "The Wealthy Hand-to-Mouth.” Brookings Papers on Economic Activity 45(1): 77-153.

Kimberlin, Sara, Jiyoon Kim, and H. Luke Shaefer. 2015, “An Updated Method for Calculating Income and Payroll Taxes from PSID Data Using the NBER's TAXSIM, for PSID Survey Years 1999 through 2011." University of Michigan manuscript.

Krueger, Alan B. 2012. "The Rise and Consequences of Inequality in the United States." Council of Economic Advisers Address, January 12, 2012.

Krueger, Dirk, Kurt Mitman, and Fabrizio Perri. 2016. "Macroeconomics and Household Heterogeniety." In Handbook of Macroeconomics Volume 2, edited by John B. Taylor and Harald Uhlig, 843-921. Amsterdam, the Netherlands: North-Holland

Lusardi, Annamaria. 1996. "Permanent Income, Current Income, and Consumption: Evidence from Two Panel Data Sets." Journal of Business and Economic Statistics 14(1): 81-90.

Misra, Kanishka, and Paolo Surico. 2014. "Consumption, Income Changes, and Heterogeneity: Evidence from Two Fiscal Stimulus Programs." American Economic Journal: Macroeconomics 6(4): 84-106.

Morgan, James N. 1971. "Static and Dynamic Responses to Food Consumption to Income." SRC working paper.

Oh, Hyunseung, and Ricardo Reis. 2012. "Targeted Transfers and the Fiscal Response to the Great Recession.” Journal of Monetary Economics 59(Supplement): S50-S64.

Piketty, Thomas, Emmanuel Saez, and Gabriel Zucman. 2018. "Distributional National Accounts: Methods and Estimates for the United States." Quarterly Journal of Economics 133(2): 553-609.

Pfeffer, Fabian T., Robert F. Schoeni, Arthur Kennickell, and Patricia Andreski. 2016. "Measuring Wealth and Wealth Inequality: Comparing Two U.S. Surveys." Journal of Economics and Social Measurement 41(2): 103-20.

Runkle, David E., 1991. "Liquidity Constraints and the Permanent-Income Hypothesis." Journal of Monetary Economics 27(1): 73-98.

Smeeding, Timothy M., and Jeffrey P. Thompson. 2011. "Recent Trends in Income Inequality." In Who Loses in the Downturn? Economic Crisis, Employment and Income Distribution (Research in Labor Economics Volume 32), edited by Herwig Immervoll, Andreas Peichi and 
Konstantinos Tatsiramos, 1-50. West Yorkshire, United Kingdom: Emerald Group

Publishing.

Stephans, Melvin Jr. 2001. "The Long-Run Consumption Effects of Earnings Shocks.” The Review of Economics and Statistics 83(1): 28-36.

Stiglitz, Joseph E., Amartya Sen, and Jean-Paul Fitoussi. 2009. Report by the Commission on the Measurement of Economic Performance and Social Progress. Paris, France: The Commission on the Measurement of Economic Performance and Social Progress.

Wolff, Edward N. 2016. "Household Wealth Trends in the United States, 1962-2013: What Happened over the Great Recession?" RSF: The Russell Sage Foundation Journal of the Social Sciences 2(6): 24-43.

Zeldes, Stephen P. 1989. "Optimal Consumption with Stochastic Income: Deviations from Certainty Equivalence.” Quarterly Journal of Economics 104(2): 275-298.

Ziliak, James P. 1998. "Does the Choice of Consumption Measure Matter? An Application to the Permanent-Income Hypothesis." Journal of Monetary Economics 41(1): 201-216. 
Figure 1A: Scatter plot of changes in income and consumption, 2005-2007

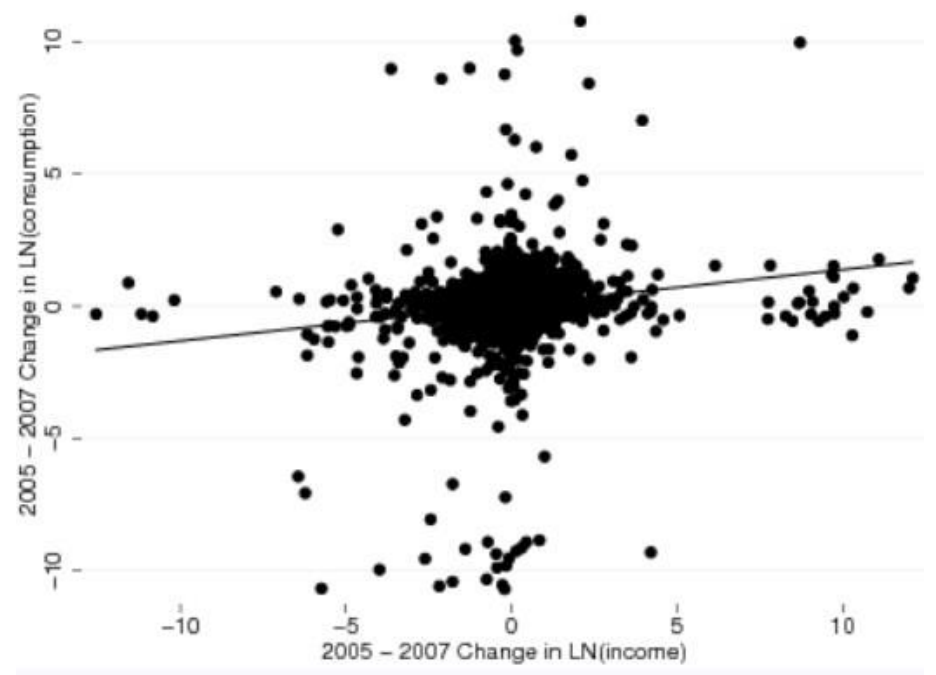

Figure 1B: Scatter plot of changes in income and consumption for top and bottom wealth quintiles, 2005-2007

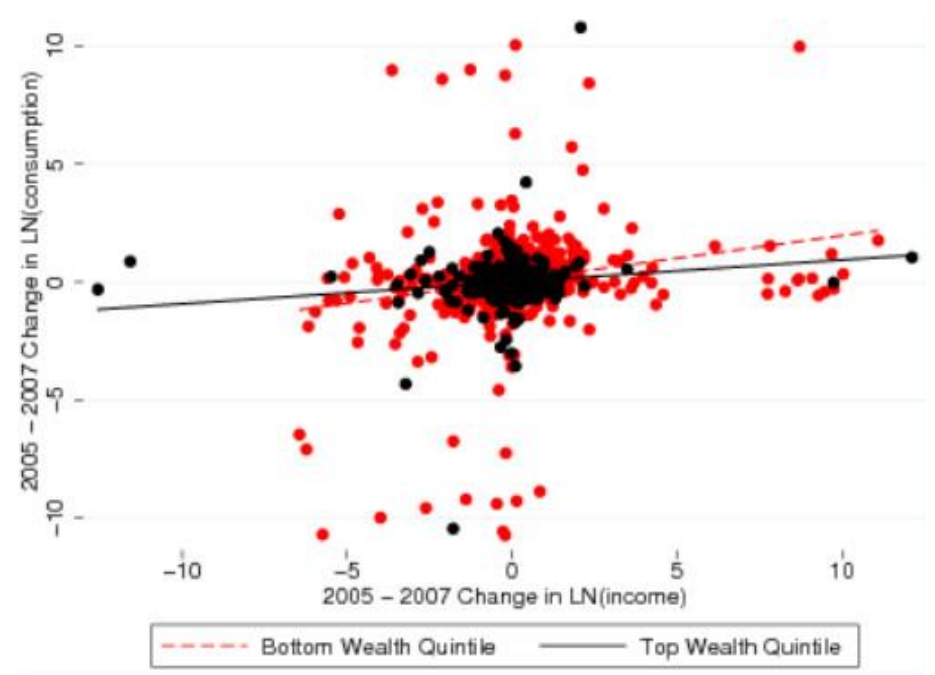

Table 1: APC by income and wealth quintile (using median of quintiles)

\begin{tabular}{lcccc}
\hline & \multicolumn{2}{c}{ Income } & \multicolumn{2}{c}{ Wealth } \\
& $\mathbf{1 9 9 9}$ & $\mathbf{2 0 1 3}$ & $\mathbf{1 9 9 9}$ & $\mathbf{2 0 1 3}$ \\
\hline Q1 & 0.976 & 0.974 & 0.654 & 0.744 \\
Q2 & 0.680 & 0.741 & 0.583 & 0.658 \\
Q3 & 0.561 & 0.629 & 0.564 & 0.590 \\
Q4 & 0.518 & 0.542 & 0.555 & 0.607 \\
Q5 & 0.435 & 0.475 & 0.582 & 0.607 \\
\hline
\end{tabular}


Table 2: Pooled Euler Equation

\begin{tabular}{|c|c|c|c|c|c|}
\hline & a & b & c & d & e \\
\hline \multirow[t]{2}{*}{$\Delta \ln Y_{t-2}$} & $0.100^{* * * *}$ & $0.095^{* * *}$ & $0.095^{* * *}$ & $0.098^{* * *}$ & $0.141^{* * *}$ \\
\hline & $(0.013)$ & $(0.013)$ & $(0.013)$ & $(0.013)$ & $(0.024)$ \\
\hline \multirow[t]{2}{*}{ Number of adults } & & $0.059^{* * * *}$ & $0.059^{* * * *}$ & $0.059^{* * * *}$ & $0.056^{* * * *}$ \\
\hline & & $(0.007)$ & $(0.007)$ & $(0.007)$ & $(0.007)$ \\
\hline \multirow[t]{2}{*}{ Number of children } & & $0.010^{* *}$ & $0.010^{* * *}$ & $0.010^{* * *}$ & $0.011^{* *}$ \\
\hline & & $(0.003)$ & $(0.003)$ & $(0.003)$ & $(0.003)$ \\
\hline \multirow[t]{2}{*}{ If change in family size } & & $-0.030^{*}$ & $-0.030^{*}$ & $-0.029^{*}$ & $-0.028^{*}$ \\
\hline & & $(0.013)$ & $(0.013)$ & $(0.013)$ & $(0.013)$ \\
\hline \multirow[t]{2}{*}{ Married } & & 0.012 & 0.012 & 0.012 & -0.015 \\
\hline & & $(0.010)$ & $(0.010)$ & $(0.010)$ & $(0.010)$ \\
\hline \multirow[t]{2}{*}{ If change in marital status } & & $-0.082^{* *}$ & $-0.082^{* *}$ & $-0.082^{* *}$ & $-0.076^{* *}$ \\
\hline & & $(0.025)$ & $(0.025)$ & $(0.025)$ & $(0.025)$ \\
\hline \multirow[t]{2}{*}{ Age } & & $-0.004^{* * * *}$ & $-0.004^{* * * *}$ & $-0.004^{* * *}$ & $-0.005^{* * *}$ \\
\hline & & $(0.000)$ & $(0.000)$ & $(0.000)$ & $(0.001)$ \\
\hline \multirow[t]{2}{*}{ Black } & & 0.000 & 0.000 & 0.001 & 0.026 \\
\hline & & $(0.014)$ & $(0.014)$ & $(0.014)$ & $(0.015)$ \\
\hline \multirow[t]{2}{*}{ Other } & & 0.022 & 0.022 & 0.022 & 0.028 \\
\hline & & $(0.014)$ & $(0.014)$ & $(0.014)$ & $(0.014)$ \\
\hline \multirow[t]{2}{*}{ Hispanic } & & $-0.053^{* *}$ & $-0.053^{* *}$ & $-0.053^{* *}$ & $-0.037^{*}$ \\
\hline & & $(0.018)$ & $(0.018)$ & $(0.018)$ & $(0.018)$ \\
\hline \multirow[t]{2}{*}{$\Delta \ln Y_{t-2}$ and debt/assets } & & & 0.000 & 0.000 & $0.000^{* *}$ \\
\hline & & & $(0.000)$ & $(0.000)$ & $(0.000)$ \\
\hline \multirow[t]{2}{*}{ Debt/assets } & & & 0.000 & 0.000 & $0.000^{*}$ \\
\hline & & & $(0.000)$ & $(0.000)$ & $(0.000)$ \\
\hline \multirow[t]{2}{*}{$\Delta \ln Y_{t-2}$ and debt/income } & & & & 0.000 & 0.000 \\
\hline & & & & $(0.000)$ & $(0.000)$ \\
\hline \multirow[t]{2}{*}{ Debt/income } & & & & 0.000 & 0.000 \\
\hline & & & & $(0.000)$ & $(0.000)$ \\
\hline$\Delta \ln Y_{t-2}$ and net assets (ln) & & & & & $\begin{array}{c}-0.006^{* *} \\
(0.002)\end{array}$ \\
\hline \multirow[t]{2}{*}{ Net assets (ln) } & & & & & $0.011^{* * *}$ \\
\hline & & & & & $(0.002)$ \\
\hline \multirow[t]{2}{*}{ Constant } & $0.053^{* * * *}$ & $0.137^{* * *}$ & $0.137^{* * *}$ & $0.136^{* * *}$ & 0.072 \\
\hline & $(0.015)$ & $(0.038)$ & $(0.038)$ & $(0.038)$ & $(0.039)$ \\
\hline Observations & 35,286 & 35,286 & 35,286 & 35,286 & 35,286 \\
\hline Clusters & 7,874 & 7,874 & 7,874 & 7,874 & 7,874 \\
\hline $\mathrm{R}^{2}$ & 0.018 & 0.027 & 0.027 & 0.027 & 0.031 \\
\hline
\end{tabular}

The dependent variable is the change in log consumption between $\mathrm{t}$ and $\mathrm{t}-2$. The demographic characteristics are measured as of $\mathrm{t}-2$, include the debt/assets and debt/income variables. State and year fixed effects are not shown; standard errors in parentheses ${ }^{*} p<0.05,{ }^{* *} p<0.01,{ }^{* * *} p<0.001$

Source: Panel Study of Income Dynamics, 1999-2013. 
Table 3: Euler Equation Estimation with Interactions with Wealth Quintile

\begin{tabular}{lc} 
& $\mathbf{b}$ \\
\hline$\Delta \ln Y_{t-2}$ & $0.141^{* * *}$ \\
$\Delta \ln Y_{t-2}$ Wealth quintile $(\mathrm{t}-2)=2$ & $-0.076^{*}$ \\
$\Delta \ln Y_{t-2}$ Wealth quintile $(\mathrm{t}-2)=3$ & -0.003 \\
$\Delta \ln Y_{t-2}$ Wealth quintile $(\mathrm{t}-2)=4$ & $-0.079^{*}$ \\
$\Delta \ln Y_{t-2}$ Wealth quintile $(\mathrm{t}-2)=5$ & $-0.112^{* * * *}$ \\
Observations & 35,286 \\
Clusters & 7,874 \\
$\mathrm{R}^{2}$ & 0.030 \\
& \\
F test of interaction terms & \\
Wealth quintile $==2 \Delta \ln Y_{t-2}$ & 0.039 \\
Wealth quintile $==3 \Delta \ln Y_{t-2}$ & 0.946 \\
Wealth quintile $==4 \Delta \ln Y_{t-2}$ & 0.018 \\
Wealth quintile $==5 \Delta \ln Y_{t-2}$ & 0.000 \\
\hline
\end{tabular}

The dependent variable is the change in log consumption between $t$ and $t-2$. Control variables for wealth quintile, race, family size, married, age, change in size/marital status, state, and year are not shown.

${ }^{*} p<0.05,{ }^{* *} p<0.01,{ }^{* * *} p<0.001$

Source: Panel Study of Income Dynamics, 1999-2013.

Table 4: Euler Equation Estimation Using Predictable Changes in Income

\begin{tabular}{|c|c|c|c|}
\hline & $\Delta \hat{y}_{t-2}$ & $\begin{array}{c}\text { (1) } \\
\Delta \hat{y}_{t-2^{+}}\end{array}$ & $\begin{array}{r}(\mathbf{2}) \\
\Delta \hat{y}_{t-2}\end{array}$ \\
\hline$\Delta \hat{y}_{t-2}$ & $0.188^{*}$ & $0.240^{*}$ & 0.161 \\
\hline$\Delta \hat{y}_{t-2}$ Wealth quintile $(\mathrm{t}-2)=2$ & $\begin{array}{c}(0.073) \\
-0.082\end{array}$ & $\begin{array}{l}(0.102) \\
-0.030\end{array}$ & $\begin{array}{c}(0.093) \\
-0.139\end{array}$ \\
\hline$\Delta \hat{y}_{t-2}$ Wealth quintile $(\mathrm{t}-2)=3$ & $\begin{array}{c}(0.126) \\
-0.019\end{array}$ & $\begin{array}{l}(0.208) \\
-0.237^{*}\end{array}$ & $\begin{array}{c}(0.121) \\
0.206\end{array}$ \\
\hline$\Delta \hat{y}_{t-2}$ Wealth quintile $(\mathrm{t}-2)=4$ & $\begin{array}{c}(0.131) \\
-0.180^{*}\end{array}$ & $\begin{array}{l}(0.118) \\
-0.237^{*}\end{array}$ & $\begin{array}{c}(0.219) \\
-0.142\end{array}$ \\
\hline$\Delta \hat{y}_{t-2}$ Wealth quintile $(\mathrm{t}-2)=5$ & $\begin{array}{l}(0.086) \\
-0.196^{*} \\
(0.081)\end{array}$ & $\begin{array}{l}(0.119) \\
-0.219^{+} \\
(0.116)\end{array}$ & $\begin{array}{l}(0.111) \\
-0.208^{*} \\
(0.101)\end{array}$ \\
\hline $\begin{array}{l}\text { Observations } \\
\text { Clusters } \\
\mathrm{R}^{2} \\
\end{array}$ & $\begin{array}{c}20,348 \\
5,664 \\
0.019 \\
\end{array}$ & $\begin{array}{c}20,348 \\
5,664 \\
0.019 \\
\end{array}$ & $\begin{array}{c}20,348 \\
5,664 \\
0.017 \\
\end{array}$ \\
\hline
\end{tabular}

Control variables for race, family size, married, age, change in size/marital status, state, and year are not shown. ${ }^{*} p<0.05,{ }^{* *} p<0.01,{ }^{* * *} p<0.001,{ }^{+} p<0.1$

Source: Panel Study of Income Dynamics, 1999-2013. The predictable changes in income are estimated following Filer and Fisher (2007). 
Table 5: Euler Equation Estimated with Alternative Models, Households and Variables

Panel A: Excluding Housing from Wealth

\begin{tabular}{lccc}
\hline & & & \\
& $\Delta \hat{y}_{t-2}$ & $\Delta \hat{y}_{t-2^{+}}$ & $\Delta \hat{y}_{t-2^{-}}$ \\
\hline$\Delta \hat{y}_{t-2}$ & $0.189^{* *}$ & $0.244^{*}$ & $0.153^{*}$ \\
$\Delta \hat{y}_{t-2}$ Wealth quintile (t-2)=2 & $(0.065)$ & $(0.090)$ & $(0.082)$ \\
& -0.101 & -0.105 & -0.094 \\
$\Delta \hat{y}_{t-2}$ Wealth quintile (t-2) $=3$ & $(0.116)$ & $(0.191)$ & $(0.119)$ \\
& -0.077 & -0.209 & 0.111 \\
$\Delta \hat{y}_{t-2}$ Wealth quintile (t-2) $=4$ & $(0.120)$ & $(0.141)$ & $(0.231)$ \\
$\Delta \hat{y}_{t-2}$ Wealth quintile (t-2) $=5$ & $-0.148^{+}$ & $-0.260^{*}$ & -0.036 \\
& $(0.076)$ & $(0.115)$ & $(0.097)$ \\
& $-0.205^{* *}$ & $-0.222^{+}$ & $-0.218^{*}$ \\
\hline
\end{tabular}

Control variables for race, family size, married, age, change in size/marital status, state, and year are not shown. ${ }^{*} p<0.05,{ }^{* *} p<0.01,{ }^{* * *} p<0.001,{ }^{+} p<0.1$

Source: Panel Study of Income Dynamics, 1999-2013. The predictable changes in income are estimated following Filer and Fisher (2007).

Panel B: Only Non-elderly Households

\begin{tabular}{lccc}
\hline & & & \\
& $\Delta \hat{y}_{t-2}$ & $\Delta \hat{y}_{t-2^{+}}$ & $\Delta \hat{y}_{t-2^{-}}$ \\
\hline$\Delta \hat{y}_{t-2}$ & $0.199^{* * *}$ & $0.258^{* * *}$ & $0.159^{*}$ \\
$\Delta \hat{y}_{t-2}$ Wealth quintile (t-2)=2 & $(0.074)$ & $(0.106)$ & $(0.050)$ \\
& -0.126 & -0.113 & -0.148 \\
$\Delta \hat{y}_{t-2}$ Wealth quintile (t-2) $=3$ & $(0.137)$ & $(0.225)$ & $(0.099)$ \\
& -0.051 & -0.261 & 0.173 \\
$\Delta \hat{y}_{t-2}$ Wealth quintile (t-2) $=4$ & $(0.149)$ & $(0.122)$ & $(0.250)$ \\
& $-0.097^{*}$ & $-0.151^{* *}$ & -0.018 \\
$\Delta \hat{y}_{t-2}$ Wealth quintile (t-2) $=5$ & $(0.078)$ & $(0.115)$ & $(0.065)$ \\
& $-0.196^{* * *}$ & $-0.252^{*}$ & $-0.157^{* *}$ \\
\hline
\end{tabular}

Control variables for race, family size, married, age, change in size/marital status, state, and year are not shown. ${ }^{*} p<0.05,{ }^{* *} p<0.01,{ }^{* * *} p<0.001,{ }^{+} p<0.1$

Source: Panel Study of Income Dynamics, 1999-2013. The predictable changes in income are estimated following Filer and Fisher (2007). 
Panel C: Using Consistent Consumption

\begin{tabular}{lccc}
\hline & $\Delta \hat{y}_{t-2}$ & $\Delta \hat{y}_{t-2^{+}}$ & $\Delta \hat{y}_{t-2^{-}}$ \\
\hline$\Delta \hat{y}_{t-2}$ & $0.187^{* * * *}$ & $0.237^{* * * *}$ & $0.167^{*}$ \\
$\Delta \hat{y}_{t-2 \text { Wealth quintile }(\mathrm{t}-2)=2}$ & $(0.071)$ & $(0.099)$ & $(0.092)$ \\
& -0.098 & -0.085 & -0.116 \\
$\Delta \hat{y}_{t-2}$ Wealth quintile (t-2) $=3$ & $(0.125)$ & $(0.211)$ & $(0.125)$ \\
& -0.042 & -0.251 & 0.164 \\
$\Delta \hat{y}_{t-2}$ Wealth quintile (t-2) $=4$ & $(0.125)$ & $(0.121)$ & $(0.205)$ \\
& -0.074 & -0.094 & -0.054 \\
$\Delta \hat{y}_{t-2}$ Wealth quintile $(\mathrm{t}-2)=5$ & $(0.145)$ & $(0.240)$ & $(0.115)$ \\
& $-0.207^{* * *}$ & $-0.237^{*}$ & $-0.218^{* *}$ \\
& $(0.080)$ & $(0.115)$ & $(0.102)$ \\
\hline
\end{tabular}

Control variables for race, family size, married, age, change in size/marital status, state, and year are not shown. ${ }^{*} p<0.05,{ }^{* *} p<0.01,{ }^{* * *} p<0.001,{ }^{+} p<0.1$

Source: Panel Study of Income Dynamics, 1999-2013. The predictable changes in income are estimated following Filer and Fisher (2007).

Panel D: Using More Comprehensive Consumption

\begin{tabular}{lccc}
\hline & $\Delta \hat{y}_{t-2}$ & $\Delta \hat{y}_{t-2^{+}}$ & $\Delta \hat{y}_{t-2^{-}}$ \\
\hline$\Delta \hat{y}_{t-2}$ & $0.148^{* * * *}$ & $0.205^{* *}$ & 0.090 \\
$\Delta \hat{y}_{t-2}$ Wealth quintile $(\mathrm{t}-2)=2$ & $(0.067)$ & $(0.098)$ & $(0.067)$ \\
& -0.046 & -0.021 & -0.048 \\
$\Delta \hat{y}_{t-2}$ Wealth quintile $(\mathrm{t}-2)=3$ & $(0.118)$ & $(0.197)$ & $(0.110)$ \\
& -0.066 & -0.238 & 0.119 \\
$\Delta \hat{y}_{t-2}$ Wealth quintile $(\mathrm{t}-2)=4$ & $(0.095)$ & $(0.141)$ & $(0.122)$ \\
& -0.110 & -0.160 & -0.046 \\
$\Delta \hat{y}_{t-2}$ Wealth quintile $(\mathrm{t}-2)=5$ & $(0.072)$ & $(0.106)$ & $(0.086)$ \\
& $-0.151^{*}$ & $-0.216^{*}$ & -0.081 \\
& $(0.078)$ & $(0.114)$ & $(0.080)$ \\
\hline
\end{tabular}

Control variables for race, family size, married, age, change in size/marital status, state, and year are not shown. ${ }^{*} p<0.05,{ }^{* *} p<0.01,{ }^{* * *} p<0.001,{ }^{+} p<0.1$

Source: Panel Study of Income Dynamics, 1999-2013. The predictable changes in income are estimated following Filer and Fisher (2007). 
Panel E: Using Food-at-Home Consumption

\begin{tabular}{lccc}
\hline & $\Delta \hat{y}_{t-2}$ & $\Delta \hat{y}_{t-2^{+}}$ & $\Delta \hat{y}_{t-2^{-}}$ \\
\hline$\Delta \hat{y}_{t-2}$ & $0.195^{* *}$ & $0.259^{* * * *}$ & 0.138 \\
$\Delta \hat{y}_{t-2}$ Wealth quintile $(\mathrm{t}-2)=2$ & $(0.067)$ & $(0.093)$ & $(0.073)$ \\
& $-0.256^{*}$ & -0.302 & $-0.246^{*}$ \\
$\Delta \hat{y}_{t-2}$ Wealth quintile $(\mathrm{t}-2)=3$ & $(0.134)$ & $(0.221)$ & $(0.135)$ \\
& 0.106 & -0.053 & 0.348 \\
$\Delta \hat{y}_{t-2}$ Wealth quintile $(\mathrm{t}-2)=4$ & $(0.133)$ & $(0.159)$ & $(0.201)$ \\
& -0.134 & -0.111 & $-0.197^{*}$ \\
$\Delta \hat{y}_{t-2}$ Wealth quintile $(\mathrm{t}-2)=5$ & $(0.132)$ & $(0.207)$ & $(0.117)$ \\
& $-0.221^{* *}$ & $-0.346^{* *}$ & -0.100 \\
& $(0.091)$ & $(0.144)$ & $(0.096)$ \\
\hline
\end{tabular}

Control variables for race, family size, married, age, change in size/marital status, state, and year are not shown. ${ }^{*} p<0.05,{ }^{* *} p<0.01,{ }^{* * *} p<0.001,{ }^{+} p<0.1$

Source: Panel Study of Income Dynamics, 1999-2013. The predictable changes in income are estimated following Filer and Fisher (2007). 